\title{
A Língua e a Literatura Italianas na Modernidade: um Diagnóstico LEOPARDIANO
}

\author{
Gisele Batista da Silva*
}

RESUMO: Este artigo apresenta alguns pontos de discussão acerca da análise leopardiana sobre a situação da língua e da literatura italianas na modernidade, destacando suas ponderações a respeito da relação necessária dessas atividades com as ilusões e a felicidade dos antigos, assim como sua crítica às limitações da razão iluminista.

PALAVRAS-CHAVE: Giacomo Leopardi; romantismo italiano; questione della lingua; literatura italiana.

ABSTRACT: Questo articolo presenta alcuni spunti di discussione sull'analisi leopardiana sulla situazione della lingua e della letteratura italiana nella modernità, sottolineando le sue ponderazioni per quanto riguarda la relazione necessaria di tali attività con le illusioni e la felicità degli antichi, ed anche la sua critica alle limitazioni della ragione illuminista.

PAROLE CHIAVE: Giacomo Leopardi; Romanticismo italiano; questione della lingua; letteratura italiana.

ABSTRACT: This article discusses about Leopardi's analysis on the situation of Italian language and literature in modernity, highlighting his reflections on the necessary relationship of these activities with the illusions and happiness of the ancients, as well as his critique of the limitation of reason in the age of enlightenment. KEYWORDS: Giacomo Leopardi; Italian Romanticism; questione della lingua; Italian literature.

* Universidade Federal do Rio de Janeiro, Rio de Janeiro, RJ (Brasil) - gisabats@gmail.com 


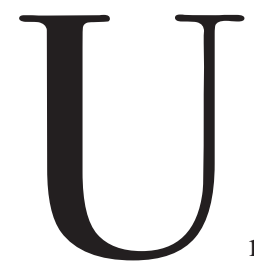

$\mathrm{m}$ dos princípios de maior valor na prática intelectual, segundo Giacomo Leopardi, era a liberdade, a mobilidade. Nele residia o caráter mais moderno de sua poética no qual, ao mesmo tempo em que denunciava o risco de uma postura supressora do passado para a força e vigência do conhecimento presente, se opunha aos modelos obsoletos de conservação da tradição. Sua ideia de liberdade sugeria tanto a confirmação da variedade e da contínua novidade na matéria linguística ("necessaria e infinita varietà delle lingue"), mas também um livre retorno do homem à familiaridade com suas origens, apontando, dessa forma, a necessidade de resgatá-las, em um movimento dialético semelhante àquele empreendido por Dante, para quem "i grandi del passato sono modelli irraggiungibili, ma al tempo stesso superati" - isto é, não eram encarados, pelo poeta oitocentista, segundo um improdutivo culto de grandeza exemplar, 
mas com eles dialogava, reconhecendo uma inteira cultura que lhes dava organização e servia de legitimação (JOSSA, 2006, p. 189).

Houve, de fato, um período áureo da cultura italiana, cujo espírito foi - segundo Leopardi impedido, limitado, esmagado, refletindo-se consequentemente no uso da língua e na produção literária dela decorrente. A visível degradação do exercício intelectual foi longamente discutida no Zibaldone di pensieri (doravante Zib) ${ }^{1}$, cujos componentes principais, a língua e a literatura, tiveram suas capacidades expressivas aviltadas, gerando graves resultados para a manifestação cultural na Itália do século XIX.

A questão da língua foi um tema fundamental não apenas para Leopardi, mas para todo o contexto literário italiano, visto que sustentou a definição e a orientação das produções até o Romantismo, determinando caminhos e traçando objetivos a alcançar. Contemporaneamente, ultrapassou as fronteiras da ficção, refletindo as contradições políticas e sociais que a península enfrentava. A busca de traços identitários e distintivos das nações europeias alimentou diferentes debates nos séculos XVIII e XIX, que ora envolveram uma polêmica literária, ora a proposição de uma dada conduta social para a língua - mas todas mantiveram vínculo com algum capítulo da memória nacional, que convidavam ao exame das questões históricas e políticas que a determinaram. Mesmo que, como assevera Stefano Jossa (2006, p. 188), atingir a identidade linguística no caso italiano tenha sido menos importante do que consolidar sua identidade literária, a língua foi inegavelmente um componente distintivo e expressivo da "questão identitária italiana", um instrumento fomentador de autoconsciência política, social e cultural.

Movido por sua sensibilidade estética, Leopardi deu origem a uma densa rede de reflexões linguísticas em seu diário intelectual, cujos variados temas alimentaram o debate acerca da conhecida questione della lingua e expressaram - mais do que a discussão de uma forma linguística ou de conteúdos - o espírito do novo homem, isto é, do homem moderno: “obiettivo di rinnovarsi nei contenuti e nelle forme, senza cessare di essere lingua italiana, senza perdere, dunque, la sua identità strutturale, appiatendosi nel modello francese" (GENSINI, 1998, p. XV). O pensamento leopardiano sobre a questão linguística na Itália não refletiu manifestamente quaisquer adesões a projetos políticos, mas foi contundente ao apontar o aprisionamento que a civiltà del sapere ${ }^{2}$, insigne prática iluminista, impunha à língua. As variadas consequências conduziam a língua italiana a um processo de decadência, barbarismo e regularidade.

Sobre a crítica de Leopardi à civiltà del sapere, compreende-se o rigor e a inflexibilidade racionalistas que se manifestavam como abstração da singularidade corpórea e sensível do

1 As próximas referências ao Zibaldone di pensieri terão apenas as iniciais da obra (Zib), seguidas do número do fragmento a que se referem.

2 Segundo Antonio Prete (2006, p. 20), era a dominação de todas as atividades imaginativas pela prática racionalista, que subtraía a ilusão da esfera cognitiva, a fim de controlá-la e encaminhá-la à zona insidiosa das ideologias. 
homem, isto é, de sua forma mais sublime de criar e construir - procedimento próprio da civilização iluminista, que subtraía do indivíduo sua condição humana, distanciando-o de um horizonte poético e recriador da vida (PRETE, 2006, p. 97). Tal crítica indicava um modo de produção de conhecimento que se transfigurava em forma de poder opressivo por meio da língua, atingindo fatalmente a fonte primeira da poesia, a imaginação, e dando origem a uma voz de tom excessivamente abstrativo. A preocupação de Leopardi concentrava-se no caminho então percorrido pela língua italiana que, envolvendo-se pela "linguagem da razão", corria o sério risco de se tornar estável, seca, árida, una, impotente. Leopardi pretendia se colocar contrário a uma língua que construísse "campi di convenzione linguistica, uniformando 'voci' e 'termini'” (PRETE, 2006, p. 72), estava o poeta defendendo uma língua enquanto instrumento de criação do pensamento - e não apenas como sua expressão -, que funcionasse como uma voz de compreensão do mundo, da natureza (GENSINI, 1998, p. XXIII), e que pudesse, consequentemente, fazer que a Itália se comunicasse com o resto da Europa.

A intensa reflexão linguística de Leopardi iniciada no fim de 1818, no momento de sua "conversão filosófica" e no auge da querela literário-cultural sobre as teses românticas, foi uma fase de seu pensamento em que um grande número de fragmentos sobre o tema linguístico no Zibaldone, mesmo que sob diferentes ângulos de abordagem, convergiram para a nítida distinção entre os modos de conhecer dos modernos e dos antigos, regidos pela racionalidade e pela imaginação, respectivamente. Das reflexões leopardianas acerca da língua, vale antecipar sua crítica mais evidente e determinante, marcada pela oposição racional e natural, cujo influxo sobre o desenvolvimento do pensamento do homem torna clara a distância entre os antigos e os modernos.

Stefano Gensini (1998) chama atenção para o fato de que, ainda que guardem diferenças substanciais, natureza e razão não pertencem a duas realidades completamente heterogêneas no pensamento leopardiano: a razão é, de fato, um dos componentes da natureza humana, e a discordância entre os dois momentos históricos (antiguidade e modernidade) se mostra no regime e na função atribuídos à atividade cognitiva: nos modernos, a razão concentra as finalidades na uniformização das línguas e dos homens (costumes e ideologias), na valorização da certeza e da segurança em detrimento da dúvida e do sonho, na prescrição de modelos rigorosos e padronizadores e, finalmente, na eficácia e imutabilidade desse padrão. Já no modelo considerado natural confluem os sentidos que, em contato com o intelecto humano, conduzem o conhecimento a novas fronteiras: guiados pela imaginação - a expressão mais direta e natural 
do ser humano, segundo Leopardi -, os sentidos são mediados e reelaborados por essa força produtiva e autônoma que funciona de forma lógica, mas sem subordinar o intelecto e com ele interagindo (GENSINI, 1998, p. XXVII).

Para Leopardi, essas ponderações mostravam-se necessárias, dada a situação italiana: uma língua vilipendiada e uma tradição literária e cultural esquecida e substituída por formas inferiores de expressão poética - pressagiava o completo enfraquecimento do spirito italiano, que se dispersava e empobrecia em meio a formas e estilos extrínsecos a sua natureza livre e versátil, herdada dos antigos. O poeta reivindicava atenção à propagação de uma estrutura linguística excessivamente racionalizante, estéril e inadequada, que se distanciava de uma relação originária com os antigos, especialmente os gregos. Para ilustrá-la, Leopardi opunha a versatilidade da língua italiana à ductilidade submissa do francês. No fragmento 30 de seu diário intelectual, o poeta de Recanati afirma que fazer-se compreender em francês era insuficiente, a língua italiana "colocava sob os olhos" a matéria poética, tornava-a sensível e visível, pois se desenvolvia na "província da imaginação", onde se fundamentava o sentido nobre e enriquecedor da palavra e do pensamento. A identificação com um ethos antigo indicava o desejo de Leopardi em resgatar o espírito clássico para debelar o moderno: "è così oltrapassato il procedimento illuministico che dissipa il mito disciplinandone i residui delle fondazioni dell'antropologia" (PRETE, 1998, p. 135). A construção do saber antigo erguia suas bases nas ilusões, um "composto ed ordine delle cose", "ingredienti essenziali del sistema della natura umana, e date dalla natura a tutti quanti gli uomini [...] senza cui la vita nostra sarebbe la più misera e barbara cosa ec." (Zib 51), às quais uma estranheza à verdade as opunha radicalmente ao mundo moderno. Das ilusões nasciam as formas mais remotas, autônomas, inócuas e harmonizadas com a finalidade primeira e natural do homem antigo, isto é, seu encontro com a felicidade.

A presença dos antigos na obra leopardiana, principalmente dos gregos, direcionou seu olhar para um vasto cenário em que a faculdade da imaginação, como faculdade criativa do homem, era convocada a fazer parte dos processos linguístico e literário. Havia, entretanto, em Leopardi, a consciência de que o novo tempo trouxera mudanças radicais e, por esse motivo, pôs-se a repensar o sistema estético e poético moderno, que levasse em consideração suas raízes clássicas, mas que também atendesse às exigências de uma nova literatura para uma Itália em transformação. Assim, a literatura clássica não poderia se colocar em continuidade direta com o presente, sob o risco de um profundo anacronismo ou teleologismo, mas deveria ser reinterpretada e reintegrada à poesia como forma de pensamento autêntico, em que a "poesia 
imaginativa" grega emprestava à "poesia sentimental” moderna sua valorização da imaginação, integrando a ela espontaneidade e sensibilidade, e minimizando suas características filosófica e racionalista. Queria Leopardi que a literatura italiana recuperasse uma relação constitutiva e direta com a natureza, típica dos antigos, a fim de restituir-lhe a consciência de felicidade do ser humano, que contrastava fortemente com a desnaturalização do mundo moderno iluminista.

A crítica leopardiana aos prejuízos e à nocividade do mundo moderno, segundo Fábio Rocha Teixeira, confrontava-o ao ideal clássico, cuja espontaneidade, naturalidade e simplicidade experimentavam a "imaginação como faculdade antropológica fundamental da vida humana e de suas criações" (TEIXEIRA, 2012, p. 181). Se comparada à razão, a imaginação tinha potencialidade infinitamente superior, pois despertava no homem os sentimentos mais sublimes, além de conduzi-lo a um conhecimento mais profundo da dimensão humana em sua estreita relação com a natureza - um par indissociável. A mitologia e a literatura clássica não eram, para Leopardi, apenas uma figura simbólica que impunha uma autoridade cultural sobre as produções modernas, mas a matriz unificante que estabelecia conexão direta entre italianos e a antiguidade greco-romana, fundamentando o futuro da cultura italiana em bases neoclássicas e alegóricas (LUZZI, 2012, p. 18), ao contrário do que desejavam alguns de seus contemporâneos românticos. Essa resistência de Leopardi a alguns aspectos da modernidade traduziu sua desconfiança em um racionalismo progressivo considerado ora infecundo ora contraproducente, e a consequente fragilização das ilusões e da imaginação, que perderiam radicalmente, nessa nova ordem, sua capacidade de enlevo e persuasão. O poeta desejava a conciliação entre tradição e inovação, "gettando i semi dell'Italia futura nel terreno del suo passato, onorando così le forme culturali perdute e gli esemplari deceduti de uno spirito italiano che aveva resistito a secoli di frammentazione politica” (LUZZI, 2012, p. 19).

A descrição desse percurso da modernidade, que penetrou em suas instituições mais significativas, reproduz o progressivo processo denominado por Leopardi spiritualizzazione, no qual a radical abstração das condições materiais e corpóreas da existência do homem, uma crescente destituição do sensível e do corpo, gerou seu enfraquecimento espiritual. Dentre as diferentes causas para essa transformação, Leopardi não poderia ignorar o surgimento do cristianismo nem o desenvolvimento da ciência e sua dedicação aos dados empíricos que desabonavam do universo cognitivo do homem sua fração imaginativa.

Em decorrência dessas mudanças, a nova imagem atribuída ao homem, uma subjetividade que prescindia do elemento corpóreo e resumia a sua especificidade a simples aspectos da interioridade, significou a passagem da centralidade das instâncias do corpo a seu completo 
esquecimento. $\mathrm{O}$ acesso ao mundo moderno, portanto, não solicitava apenas um empobrecimento axiológico da matéria em favor do espírito, mas postulava o deslocamento completo de tudo que era singular e concreto para o mundo das abstrações (BIANCU, 2012, p. 31).

Partindo dos processos cognitivos, Leopardi dedicou atenção a dois componentes que reverberavam diretamente na vida social e cultural italiana: a língua e a literatura. A primeira, com sua incontestável importância na expressão dos saberes, buscava afirmar-se em meio ao difundido francesismo manifesto na língua italiana cotidiana, em que "l'invasione francese porta nuovi francesismi, neologismi amministrativi - e un'ondata di retorica” (MIGLIORINI, 2010, p. 530). A sujeição ao "bello scrivere" foi apenas um dos tópicos alarmantes que Leopardi entreviu naquele momento histórico da Itália e, como notável filólogo, foi capaz de identificar os grilhões racionalistas a que às línguas europeias estavam sujeitas.

Leopardi exprimiu constantemente sua preocupação com o andamento do italiano: "noi siamo fermati, e la lingua nostra non fa più progressi" (Zib 777) - afirmando sua compreensão da língua como atividade, em constante movimento e progressão, ele não tolerava vê-la imóvel, passiva às transformações do pensamento humano. Temia, ainda, que o rumo encontrado fosse o do completo estranhamento de si, entregando-se ao regno straniero (Zib 779), que a descaracterizaria completamente, oprimindo seu espírito, tornando-a irreconhecível e inexprimível a seus próprios falantes nativos. Depreende-se, portanto, que em qualquer golpe ou ferimento na estrutura ou no funcionamento da língua estaria a desarticulação do conjunto linguístico que dá coesão e mesmo existência e visibilidade ao povo que representa. Essa "ferida linguística" não se restringe à deformação da estrutura formal de significantes e significados, mas por meio da língua se ressente e articula a desfiguração dos costumes, da imaginação, do poder criativo, da indole, da figura de um povo: "La soverchia ristrettezza e superstizione e tirannia in ordine alla purità della lingua, ne produce dirittamente la barbarie e licenza, come la eccessiva servitù produce la soverchia e smoderata libertà dei popoli" (Zib 985).

Toda a reflexão que Leopardi destinou à língua estendeu-se à literatura. $\mathrm{O}$ grau de decadência em que se encontrava a literatura italiana de fins do século XVIII e das primeiras décadas do XIX reafirmava suas análises sobre o tratamento dado à matéria linguística, que se apresentava cada vez mais distante da totalidade que uniria falantes e escritores e daria expressão para a produção literária italiana fora de seu território: “l'influenza de' parlatori è somma, ma minore assai, se non cospira con quella degli scrittori, se per mezzo di essa non si viene a capo di mettersi in relazione col resto della nazione, colla totalità per così dire di essa" (Zib 840). 
Onde a língua italiana fosse irregular, variável, subordinatissima allo scrittore, versátil em diversos estilos, colorida, corajosa e suscetível aos riscos (Zib 688-689), lá se expressaria sua natureza mais íntima, reconhecível pela espontaneidade e desafetação de sua forma, refletida em cada palavra ou conteúdo tratado - "perché l'influenza degli scrittori era somma nel propagare una lingua" (Zib 839). No entanto, os diversos autógrafos do Zibaldone di pensieri que tratam do "enfraquecimento" da literatura italiana provam que seu percurso era, naquele momento, de decadência e esmorecimento. Em 8 de dezembro de 1820, Leopardi lamentou a substituição da originalidade de Dante e Petrarca pela regularidade da língua e pela extinção da liberdade na literatura moderna: "La letteratura italiana non è stata più propriamente originale e inventiva. L'Alfieri è un'eccezione, dovuta al suo spirito libero, e contrario a quello del tempo, e alla natura de' governi sotto cui visse" (Zib 393). Ter um espírito livre e se colocar não em conformidade e segurança, mas em argumentação com o tempo vivido, rendeu a Vittorio Alfieri uma posição distinta a de seus contemporâneos, conquanto sua formação cultural ainda possuísse muito do racionalismo iluminista. Talvez essa lembrança no Zibaldone se deva à "piemontesità" de Alfieri que, de certa forma, aludia ao esforço de Dante na formulação e consolidação de uma língua italiana com fontes populares. Dante e Petrarca deixaram para a literatura italiana um legado linguístico e literário que, segundo Leopardi, fora ignorado por muitos escritores posteriores, exceto por alguns prosadores do Cinquecento "ottimo ed aureo secolo della letteratura italiana" (Zib 695). Leopardi notou que à Itália faltava uma literatura, isto é, faltava uma fonte de representação do espírito nacional, e nela prevalecia o "amore cieco e imitazione delle cose straniere" (Zib 865).

Língua e literatura estavam, por motivos evidentes, entrelaçados na crítica leopardiana: língua empobrecida, literatura de pouca qualidade; língua corrompida, literatura meramente imitativa. Tendo uma literatura de pouca originalidade e de muita imitação, Leopardi demonstrava sua preocupação com a falta de "italianidade" dessas produções, isto é, com a ausência de expressão do povo e de seu tempo, que oprimidas pela afetação externa, desfiguradora, acabavam por fomentar um modelo cultural que não exprimia a vocação natural dos italianos e de sua língua para a arte, a literatura e a filosofia. Sem literatura propriamente italiana ou moderna, a Itália repercutia, segundo Leopardi, o desconhecimento de si e a consequente negligência à própria cultura, desprovendo-a de seu caráter tradicional (e, portanto, formador), original e de estilo nobre:

Nondimeno è sempre vero che la letteratura italiana è la più antica delle viventi, perchè Dante, Petrarca Boccaccio sono i più antichi classici fra' moderni, i più 
antichi che si leggano e nominino, non solo fra gli eruditi nazionali, ma fra tutti i colti d'Europa. (Zib 4413).

De sua crítica à civiltà del sapere, à excessiva racionalização da língua e do pensamento, à dominação do estilo externo, estranho à indole local e à perda do estilo cinquecentesco pelo assenhoreamento da cultura italiana pela francesa, ficou a pergunta, algumas vezes repetidas pela análise e censura no Zibaldone di pensieri, que animou questões relativas à língua e à literatura no interior da cultura italiana - "se l'Italia non ha letteratura che si possa chiamar moderna [...] non le si possa niente aggiungere di perfezione nè di ricchezza $[. .$.$] quando è costantissimo che$ nessuna lingua si perfeziona se non per mezzo della letteratura?” (Zib 1059).

\section{Referências}

BIANCU, S. Saggio sull'autorità. Milano: EDUCatt, 2012.

GENSINI, S. (org.). La varietà delle lingue. Pensieri sul linguaggio, lo stile e la cultura italiana. Firenze: La Nuova Italia, 1998.

JOSSA, S. L'Italia letteraria. Bologna: Il Mulino, 2006.

LEOPARDI, G. Zibaldone di pensieri. A cura di Giuseppe Pacella. Milano: Garzanti, 1991.

LUZZI, J. Il romanticismo italiano e l'Europa. Fantasia e realtà nell' 'immaginario occidentale. Roma: Carocci, 2012.

MIGLIORINI, B. Storia della lingua italiana. Milano: Bompiani, 2010.

PRETE, A. Finitudine e infinito. Milano: Feltrinelli, 1998. . Il pensiero poetante. Saggio su Leopardi. Milano: Feltrinelli, 2006.

TEIXEIRA, F. R. Fim do ethos antigo e ocaso das ilusões. Giacomo Leopardi e a modernidade. 2012. 227 f. Tese (Doutorado em Filosofia) - Faculdade de Filosofia, Letras e Ciências Humanas da Universidade de São Paulo, São Paulo, 2012.

Recebido em 10/04/2016

Aprovado em 30/05/2016 